\title{
Decompressive craniectomy for severe traumatic brain injury patients with fixed dilated pupils
}

\author{
This article was published in the following Dove Press journal: \\ Therapeutics and Clinical Risk Management \\ 22 October 2015 \\ Number of times this article has been viewed
}

\author{
Xiang Mao, ${ }^{1,3-5, *}$ \\ Guozhuan Miao6,* \\ Shuyu $\mathrm{HaO}^{2-5, *}$ \\ Xiaogang $\mathrm{TaO}^{2-5}$ \\ Zonggang $\mathrm{Hou}^{2-5}$ \\ Huan $\mathrm{Li}^{2-5}$ \\ Runfa Tian ${ }^{2-5}$ \\ Hao Zhang ${ }^{1-6}$ \\ Te $\mathrm{Lu}^{2-5}$ \\ Jun $\mathrm{Ma}^{7}$ \\ Xiaodong Zhang' \\ Hongwei Cheng' \\ Baiyun $\mathrm{Liu}^{2-6}$
}

'Department of Neurosurgery, The First Affiliated Hospital of Anhui Medical University, Hefei, Anhui, ${ }^{2}$ Department of Neurosurgery, Beijing Tian Tan Hospital, Capital Medical University, ${ }^{3}$ Nerve Injury and Repair Center of Beijing Institute for Brain Disorders, ${ }^{4}$ Neurotrauma Laboratory, Beijing Neurosurgical Institute, Capital Medical University, ${ }^{5} \mathrm{China}$ National Clinical Research Center for Neurological Diseases, ${ }^{6}$ Department of Neurotrauma, General Hospital of Armed Police Forces, ${ }^{7}$ Imaging Center of Neuroscience, Beijing Tian Tan Hospital, Capital Medical University, Beijing, People's Republic of China

*These authors contributed equally to this work

\begin{abstract}
Objective: The outcome of decompressive craniectomy (DC) for severe traumatic brain injury (sTBI) patients with fixed dilated pupils (FDPs) is not clear. The objective of this study was to validate the outcome of DC in sTBI patients with FDPs.

Patients: We retrospectively collected data from 207 sTBI patients with FDPs during the time period of May 4, 2003-October 22, 2013: DC group $(n=166)$ and conservative care (CC) group $(n=41)$.
\end{abstract}

Measurements: Outcomes that were used as indicators in this study were mortality and favorable outcome. The analysis was based on the Glasgow Outcome Scale recorded at 6 months after trauma.

Results: A total of $49.28 \%$ patients died (39.76\% [DC group] vs $87.80 \%$ [CC group]). The mean increased intracranial pressure values after admission before operation were $36.20 \pm 7.55 \mathrm{mmHg}$ in the DC group and $35.59 \pm 8.18 \mathrm{mmHg}$ in the CC group. After performing DC, the mean ICP value was $14.38 \pm 2.60 \mathrm{mmHg}$. Approximately, 34.34\% sTBI patients with FDPs in the DC group gained favorable scores and none of the patients in the CC group gained favorable scores.

Conclusion: We found that DC plays a therapeutic role in sTBI patients with FDPs, and it is particularly important to reduce intracranial pressure as soon as possible after trauma. For the patients undergoing DC, favorable outcome and low mortality could be achieved.

Keywords: decompressive craniectomy, severe traumatic brain injury, fixed dilated pupils, intracranial pressure

\section{Introduction}

Every year, $2 \%$ of the population suffer traumatic brain injury (TBI), and it is the major cause of death and disability among young people. ${ }^{1}$ Specifically, the highest mortality is seen in patients with fixed dilated pupils (FDPs) caused due to cerebral herniation, which is the result of the increased refractory intracranial pressure (rICP) due to intracranial hemorrhage or traumatic edema within 3 hours after severe TBI (sTBI). Since different standards for trauma classification are available, reports about the mortality are not consistent (from $60 \%$ to $100 \%$ ). ${ }^{2}$ According to the guidelines for the management of $\mathrm{TBI},{ }^{3}$ treatment of sTBI is performed by a combination of treatments.

It showed that DC may improve intracranial hypertension, functional outcome, and mortality in previous studies. ${ }^{4,5}$ However, Cooper et $\mathrm{al}^{6}$ showed that the use of craniectomy, as compared with standard care, decreased the mean ICP, but was associated with a worse Glasgow Outcome Scale (GOS) outcome at 6 months. The RESCUE-ICP trial (ISRCTN66202560) is currently in progress to determine whether craniectomy improves outcome in the management of TBI (our study is part of the trial). ${ }^{7}$ Though
Correspondence: Baiyun Liu Department of Neurosurgery, Beijing Tian Tan Hospital, Capital Medical University, 100050 Beijing, People's Republic of China Email liubaiyun1212@।26.com 
the importance of DC in the treatment of patients with FDPs due to cerebral herniation has been demonstrated in some studies, there are no details of the results to confirm or refute the effectiveness of DC in those studies. ${ }^{8}$

To evaluate the therapeutic effects and the outcomes of DC on sTBI patients with FDPs due to cerebral herniation, we retrospectively collected cases between 2003 and 2013.

\section{Methods}

\section{Patients and grouping}

During the time period from May 4, 2003 to October 22, 2013, a total of 5,743 patients who were admitted into our departments and treated for TBI were identified. We retrospectively collected data from those who had a history of TBI and inclusion criteria were a primary score of 3-8 on the Glasgow Coma Scale (GCS), were between the ages of 30 and 50 years, had unilateral (UFDPs) or bilateral FDPs (BFDPs, pupillary size $\geq 4 \mathrm{~mm}$ was considered dilated, associated with very sluggish or absent light responses), arrived in our hospitals within 2 hours after trauma, had undergone treatment by DC at approximately 2 hours after admission; excluded criteria were having any previous disabled neurological disease, previous craniectomy, spinal cord injury, penetrating head injury, alcohol intoxication, or no ICP monitoring. This study was approved by the Ethical Committee of the Capital Medical University of Beijing, and individual consent from participants was waived by the committee.

We divided the patients into two subgroups: DC group and conservative care (CC) group. In the $\mathrm{CC}$ group, the family members of patients requested that patients were only treated with ICP monitoring and other treatments and did not undergo DC.

\section{Treatments}

After admission, anamnesis and physical examination were conducted for all the patients. Tracheotomy was performed when necessary. All the patients included in the study were treated in intensive care units (ICUs) with advanced neurosurgical management capabilities and equipments The units also had facilities to perform ICP monitoring using a parenchymal catheter (Camino, San Diego, CA, USA) or external ventricular drain, and ICP was recorded continuously during the treatment period. The patients accepted optimized sedation, normalization of arterial carbon dioxide pressure, and use of mannitol (average amount received in subsequent 8-hour period was $250 \mathrm{~mL}$ of $20 \%$ mannitol). Special attention was paid to maintaining the internal environment to ensure proper functioning of the important organs, such as the heart, lung, liver, and kidney.

\section{Decompressive craniectomy}

A standardized surgical approach, which was modeled on the Liu et al's ${ }^{9}$ technique, was used. This approach included the unilateral craniectomy or bilateral craniectomy opening to maximize the reduction in ICP. The type of craniectomy to be performed (unilateral/bilateral) was decided based on the computed chromatography (CT) scan results. The unilateral craniectomy was performed in patients with unilateral swelling; however, in cases with general swelling, we chose to perform a bilateral craniectomy. The area covered in unilateral craniectomy was approximately $12 \mathrm{~cm} \times 15 \mathrm{~cm}$, and that in the bilateral craniectomy was nearly $10 \mathrm{~cm} \times 25 \mathrm{~cm} .{ }^{9}$ Cranioplasty was done approximately 3-4 months after craniectomy if swelling and infection had been completely resolved.

Postoperative therapy was similar to that previously described, which included keeping the respiratory tract unobstructed, balancing water and electrolyte levels, controlling the blood glucose level and body temperature, preventing dehydration and diuresis, maintaining homeostasis balance, and protecting from infections by using sensitive antibiotics, and so on. ${ }^{10-14}$

The patients in the $\mathrm{CC}$ group received all the treatments similar to those performed in the DC group, but they did not undergo craniectomy.

\section{Outcome}

During the recovery phase, the Glasgow Outcome Scale (GOS) was used for the assessment of clinical status. Three trained assessors recorded the GOS score on telephone. The outcome that was measured was the GOS score of the patients at 6 months after trauma: a composite of death, a vegetative state, severe disability, moderate disability, mild or no disability (a score of 1-5, respectively, on the GOS). ${ }^{15-18}$

\section{Statistical analysis}

All the data were presented as mean \pm standard deviation. Comparisons between data groups were performed with SPSS for Windows, version 17.0 (SPSS Inc., Chicago, IL, USA). Chi-square tests of independence for categorical variables and two-sample $t$-tests for continuous variables were used to compare unadjusted data; Mann-Whitney $U$-tests were used for continuous variables that were not normally distributed. $P$-value of less than 0.05 was considered to indicate statistical significance. 


\section{Results}

During the 10-year study period, 5,743 TBI patients were admitted to our departments. We collected data from 207 patients who were divided into two groups: DC group $(n=166)$ and CC group $(n=41)$. The characteristics of the patients are shown similar in all respects that we listed (Table 1). The mean age was $40.75 \pm 4.60$ years in the DC group (126 males, 40 females) and was $41.20 \pm 5.35$ years in the CC group (31 males, 10 females). The mean GCS was $4.73 \pm 1.44$ in the DC group. The CC group also showed similar mean GCS (5.02 \pm 1.56$)$. The mean time from trauma to treatment was similar in the two groups (Table 1). Patients in the two study groups received similar volumes of mannitol (data not shown). The mean time from admission to surgery in the DC group was $1.4 \pm 0.2$ hours (data not shown). Detailed information regarding the characteristics of the patients is given in Table 1. There was no difference with regard to age, sex, GCS, pupils, or the mean time from trauma to treatment (Table 1) between the DC and the CC groups.

The mean ICP values after admission were $36.20 \pm 7.55 \mathrm{mmHg}$ in the DC group and $35.59 \pm 8.18 \mathrm{mmHg}$ in the CC group (Table 1). Mean ICP value decreased dramatically after performing DC procedure and was found to be $14.38 \pm 2.60 \mathrm{mmHg}(P<0.0001)$. As demonstrated in Figure 1, the difference between the $\mathrm{DC}$ and the $\mathrm{CC}$ groups in mean daily ICP values was statistically significant $(P<0.01)$ $(14.38 \pm 2.60 \mathrm{mmHg}, 15.43 \pm 2.84 \mathrm{mmHg}, 17.04 \pm 3.37 \mathrm{mmHg}$, $19.22 \pm 3.19 \mathrm{mmHg}, 18.44 \pm 3.61 \mathrm{mmHg}, 20.57 \pm 3.99 \mathrm{mmHg}$, $18.82 \pm 3.17 \mathrm{mmHg}$ vs $49.95 \pm 8.75 \mathrm{mmHg}, 52.16 \pm 5.78 \mathrm{mmHg}$, $45.98 \pm 6.44 \mathrm{mmHg}, 35.17 \pm 4.26 \mathrm{mmHg}, 34.43 \pm 4.22 \mathrm{mmHg}$, $29.20 \pm 4.59 \mathrm{mmHg}, 23.95 \pm 2.04 \mathrm{mmHg}$, respectively).

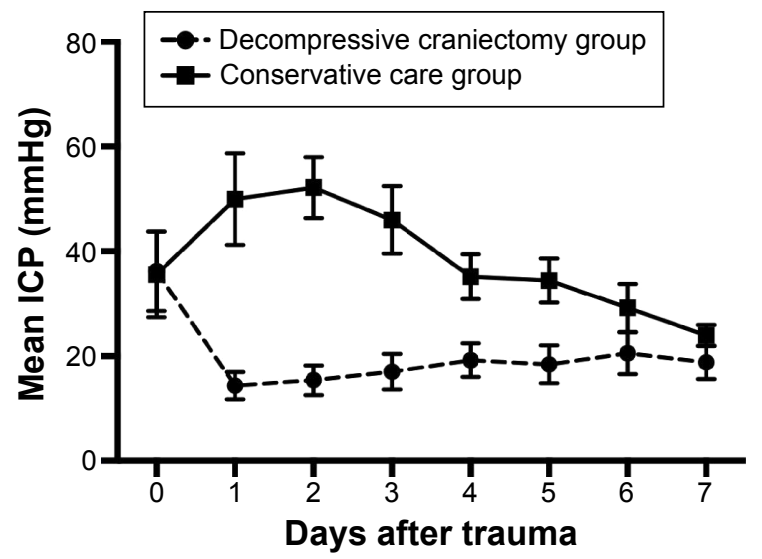

Figure I The mean measurements of intracranial pressure (ICP) in the two study groups I hour before and 7 days after treatment.

Note: The error bars indicate standard deviation.

However, there was a gradual increase after an initial marked decrease. At 6 days after DC in the DC group, the ICP values increased at approximately $20 \mathrm{mmHg}$ (Figure 1).

The mortality rate was $39.76 \%$ in the DC group, while it was $87.80 \%$ in the CC group, which was statistically different $(P<0.001$, Table 2$)$. The mortality of patients with BFDPs in the DC group was $59.46 \%$ and that in the CC group was $100 \%$. Patients with UFDP showed similar results $(34.11 \%$ [DC] vs $80.00 \%$ [CC] groups). Moreover, $97.22 \%$ of the patients died within 3 days after trauma in the CC group, among which $74.29 \%$ of the deaths occurred within 24 hours. In the DC group, $7.58 \%$ patients died within 24 hours, and $39.39 \%$ of the deaths were observed within 3 days after trauma, but the mortality rate decreased gradually after 1 week (Figure 2A). In addition, patients became deceased because of multiple organ failure, chronic body consumption,

Table I Baseline characteristics of the patients

\begin{tabular}{|c|c|c|c|}
\hline Characteristic & $\begin{array}{l}\text { Decompressive craniectomy } \\
(\mathrm{N}=166)\end{array}$ & $\begin{array}{l}\text { Conservative care } \\
(\mathrm{N}=\mathbf{4} \text { I) }\end{array}$ & $P$-value \\
\hline Age (years), mean $\pm S D$ & $40.75 \pm 4.60$ & $41.20 \pm 5.35$ & 0.59 \\
\hline \multicolumn{4}{|l|}{ Sex } \\
\hline Male & 126 & 31 & \\
\hline Female & 40 & 10 & \\
\hline GCS, mean $\pm S D$ & $4.73 \pm 1.44$ & $5.02 \pm 1.56$ & 0.25 \\
\hline $\mathrm{ICP}$ (admission), $\mathrm{mmHg}$, mean $\pm \mathrm{SD}$ & $36.20 \pm 7.55$ & $35.59 \pm 8.18$ & 0.65 \\
\hline \multicolumn{4}{|l|}{ Reactivity of pupils (\%) } \\
\hline Unilateral & I29/I66 (77.7I) & $25 / 4 I(60.98)$ & \\
\hline Bilateral & $37 / 166(22.29)$ & $|6 / 4|(39.02)$ & \\
\hline \multicolumn{4}{|l|}{ Mechanism of brain injury } \\
\hline Motor vehicle (\%) & $135(81.33)$ & $32(78.05)$ & \\
\hline Fall (\%) & $23(13.86)$ & $7(17.07)$ & \\
\hline Other (\%) & $8(4.8 \mathrm{I})$ & $2(4.88)$ & \\
\hline Time from trauma to treatment (hours), mean \pm SD & $1.5 \pm 0.7$ & $1.3 \pm 0.6$ & 0.10 \\
\hline
\end{tabular}

Abbreviations: GCS, Glasgow Coma Score; ICP, intracranial pressure; SD, standard deviation. 
Table 2 Mortality and survival in different treatments

\begin{tabular}{llll}
\hline & Mortality (\%) & Survival (\%) & Total \\
\hline Decompressive craniectomy & $66(39.76)$ & $100(60.24)$ & 166 \\
Unilateral & $44(34.11)$ & $85(65.89)$ & 129 \\
Bilateral & $22(59.46)$ & $15(40.54)$ & 37 \\
Conservative care & $36(87.80)$ & $5(12.20)$ & $4 \mathrm{I}$ \\
$\quad$ Unilateral & $20(80.00)$ & $5(20.00)$ & 25 \\
Bilateral & $16(100.00)$ & $0(0.00)$ & 16 \\
Total (\%) & $102(49.28)$ & $105(50.72)$ & 207 \\
\hline
\end{tabular}

Notes: Mortality and survival in different treatments show that the patients undergoing decompressive craniectomy could achieve lower mortality $(P<0.00 \mathrm{I})$ than that in the conservative care group.

or severe infection (between 1 week and 6 months after trauma). The results obtained in our study showed that emergency DC decreases mortality and extends survival duration in TBI patients (Figure 2).

Six months after trauma, the GOS scores were better in the DC group than in the CC group (Table 3). Favorable outcomes (GOS, 4-5) occurred in 57 patients $(34.33 \%)$ in the DC group and none occurred in the CC group. However, unfavorable outcomes were observed in 109 patients $(65.67 \%)$ in the DC group and in 41 patients $(100 \%)$ in the CC group. The difference in the GOS scores for favorable and unfavorable outcomes between the two groups was statistically significant $(P<0.001)$.

\section{Discussion}

In this study, we collected information regarding therapy and outcomes of sTBI patients with FDPs. Many studies have evaluated management and outcomes of patients with craniotomy for intracranial mass lesions in sTBI. ${ }^{19}$ More importantly, our results also show that DC is correlation to outcomes of sTBI patients with FDPs.

\section{Overall outcome}

A total of $49.28 \%$ of our patients died (39.76\% [DC group] vs $87.80 \%$ [CC group]). The mortality of patients with BFDPs

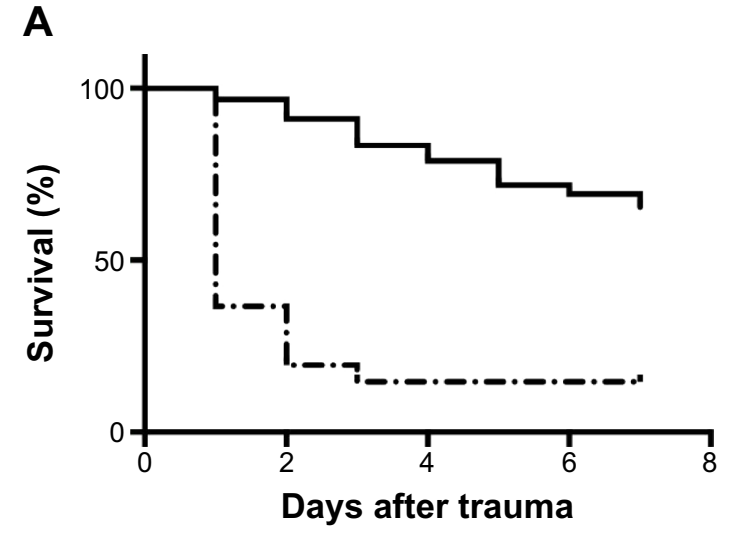

B

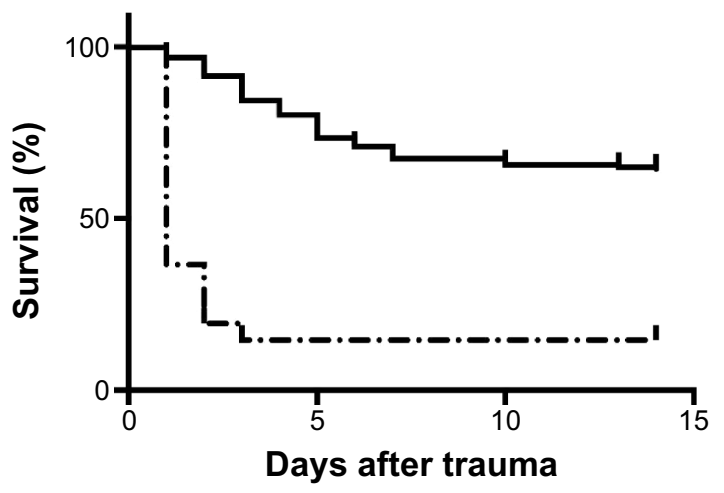

ـ Decompressive craniectomy group $\boldsymbol{\sim}$... Conservative care group

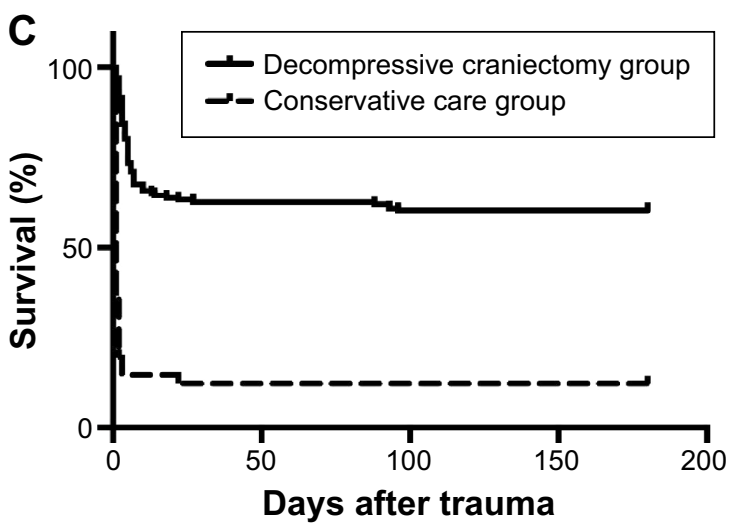

Figure 2 The survival of patients in different groups over time.

Notes: (A) The survival of patients in different groups in one week. (B) The survival of patients in different groups in two weeks. (C) The survival of patients in different groups in six months. The deceased cases occurred within 3 days after trauma in conservative care group, among which $72.22 \%$ occurred within 24 hours; while $81.82 \%$ of the cases occurred within I week in the decompressive craniectomy group, in which the highest mortality (approximately $45 \%$ ) was observed between 3 days and I week and the mortality decreased gradually after that $(P<0.00 \mathrm{I})$. 
Table 3 Glasgow Outcome Scale (GOS)

\begin{tabular}{lll}
\hline Outcome & $\begin{array}{l}\text { Decompressive craniectomy } \\
(\mathbf{N}=166)\end{array}$ & $\begin{array}{l}\text { Conservative care } \\
(\mathbf{N}=\mathbf{4 I})\end{array}$ \\
\hline GOS (\%) & & \\
5 (mild or no disability) & $20(12.05)$ & $0(0)$ \\
4 (moderate disability) & $37(22.29)$ & $0(0)$ \\
3 (severe disability) & $32(19.28)$ & $\mathrm{I}(2.43)$ \\
2 (vegetative state) & II (6.63) & $4(9.76)$ \\
I (death) & $66(39.75)$ & $36(87.81)$ \\
Favorable score of 4 to $5(\%)$ & $57(34.34)$ & $0(0)$ \\
\hline
\end{tabular}

Notes: Favorable outcomes (GOS, 4-5) occurred in 57 patients (34.34\%) in the decompressive craniectomy group and none occurred in the conservative care group $(P<0.01)$.

who had undergone decompressive craniectomy was between $70 \%$ and $90 \%,{ }^{8,20-24}$ and we found that only a few studies have shown mortality between $30 \%$ and $65 \%$, which accords with our results. Table 2 shows the relationship between mortality and different treatments. The mortality of patients with BFDPs in DC group was $59.46 \%$ and that in CC group was $100 \%$. Patients with UFDP showed similar results $(34.11 \%$ [DC group] vs $80.00 \%$ [CC group]). Our findings showed that mortality was lower in patients who had undergone decompressive craniotomy than in those who had undergone conservative care.

\section{Causes of FDPs in patients with sTBI}

UFDPs are caused due to uncal herniation, which is related to third cranial nerve compression at the tentorial edge. On the other hand, it is thought that BFDPs are caused due to alterations in the upper brain stem. ${ }^{25,26}$ Because of raised ICP in the sTBI patients, the cerebral blood flow changed after DC. The damage to brain stem circulation is a major contributing factor to BFDPs. ${ }^{27}$ The causes that lead to BFDPs in patients with sTBI are different; so, in many cases, at least in early stages, UFDP and BFDPs exhibit similar symptoms but with different pathophysiology.

\section{Decompressive craniotomy and ICP in sTBI patients with FDPs}

It shows that the indications for DC in sTBI patients are the appearance of diffuse unilateral or bilateral brain swelling with clinical deterioration; worsening of GCS score and/or FDPs; increase in rICP to $>30 \mathrm{mmHg}$; and initial GCS score of $\geq 4$ or a GCS score of at least 4 on the first posttraumatic day. ${ }^{4,10,28-30}$ Other studies ${ }^{10,30}$ reported that patients with an initial and persisting GCS score of 3 and/or BFDPs did not undergo DC. In the present study, DC was performed with an aim to reduce ICP and decrease mortality. We found that the reduction of ICP was significant following the DC procedure in the DC group, thus reaching our aim. This ICP-lowering effect of DC has been used as a means to prevent uncontrolled increases in ICP and minimize the effects of the secondary damage associated with increased ICP in the early stage. ${ }^{31}$

A rapid increase in ICP was observed in the CC group. Finally, we accomplished the ultimate goal of achieving a pressure of $20 \mathrm{mmHg}$. Other studies reported an increase in ICP at 12 hours after DC procedure was performed, which is in accordance with the results obtained in our study. ${ }^{32} \mathrm{We}$ think the increase in ICP after the initial reduction might be related to the changed environment of the brain. It is to allow for maximal swelling of the brain due to DC, avoiding an increase in $\mathrm{rICP}$.

To achieve ICP reduction, it is necessary to have sufficient space, and this can be obtained by the performing DC. We have found only two publications that have reported on the area after DC in patients with sTBI and FDPs. ${ }^{29,33}$ We think that the size gain in our patients was sufficient to provide brain volume expansion.

\section{Glasgow Outcome Scale}

The GOS is the most widely used method to evaluate patients' functional status after TBI. Trained assessors recorded the GOS score on telephone after 6 months. However, few studies assessed the results of DC outcome of TBI in patients with FDPs. Some studies concluded that patients with an initial GCS of 3 and BFDPs have no chance of recovery or experience $100 \%$ in-hospital mortality. ${ }^{22,24}$ However, in our study, $39.53 \%$ sTBI patients with UFDP and $16.22 \%$ sTBI patients with BFDPs in the DC group gained favorable scores and but none of the patients in the $\mathrm{CC}$ group showed favorable scores. Because of the reduction of ICP, cerebral blood flow and metabolism improved. Therefore, our data indicate that DC is a significant step in the surgical treatment after traumatic brain injury, and patients may benefit from this surgical treatment. 


\section{Limitation}

Some limitations in our study should be noted. The main limitation was the difference in the number of patients in the two groups at hospital admission.

\section{Conclusion}

In conclusion, we found that DC plays a therapeutic role in sTBI patients with FDPs, and it is particularly important to reduce ICP as early as possible after trauma. For the patients undergoing DC, favorable outcome and low mortality could be achieved.

\section{Acknowledgments}

This study was supported by National Natural Science Foundation of China (No 81171144, No 81471238, No 81341059, No 81371610), Beijing Nova program (No 2012033), and National Key Technology Research and Development Program of the Ministry of Science and Technology of China (2013BAI09B03).

\section{Disclosure}

The authors report no conflicts of interest in this work.

\section{References}

1. Bullock MR, Chesnut R, Ghajar J, et al. Surgical management of traumatic parenchymal lesions. Neurosurgery. 2006;58:S25-S46; discussion Si-Siv.

2. Wan J, Yuan X, Ding B. The experience of treatments of traumatic brain injury patients with bilateral fixed dilated pupil. Chinese J Clin Neurosurg. 2003;8:115.

3. The Brain Trauma Foundation. The American Association of Neurological Surgeons. The Joint Section on Neurotrauma and Critical Care. Critical pathway for the treatment of established intracranial hypertension. J Neurotrauma. 2000;17:537-538.

4. Polin RS, Shaffrey ME, Bogaev CA, et al. Decompressive bifrontal craniectomy in the treatment of severe refractory posttraumatic cerebral edema. Neurosurgery. 1997;41:84-92; discussion 92-84.

5. Aarabi B, Hesdorffer DC, Ahn ES, Aresco C, Scalea TM, Eisenberg HM. Outcome following decompressive craniectomy for malignant swelling due to severe head injury. J Neurosurg. 2006;104:469-479.

6. Cooper DJ, Rosenfeld JV, Murray L, et al. Decompressive craniectomy in diffuse traumatic brain injury. N Engl J Med. 2011;364:1493-1502.

7. Timofeev I, Kirkpatrick PJ, Corteen E, et al. Decompressive craniectomy in traumatic brain injury: outcome following protocol-driven therapy. Acta Neurochir Suppl. 2006;96:11-16.

8. Goksu E, Ucar T, Akyuz M, Yilmaz M, Kazan S. Effects of decompressive surgery in patients with severe traumatic brain injury and bilateral non-reactive dilated pupils. Ulus Travma Acil Cerrahi Derg. 2012; 18:231-238.

9. Liu B, Jiang J, Zhang S. The introduction of decompressive craniectomy for traumatic brain injury patients. Chinese J Neurosurg. 2008;24: $153-154$.

10. Guerra WK, Gaab MR, Dietz H, Mueller JU, Piek J, Fritsch MJ. Surgical decompression for traumatic brain swelling: Indications and results. J Neurosurg. 1999;90:187-196.

11. Liu WG, Qiu WS, Shen H, Wang WM. Management of posttraumatic brain swelling based on clinical typing. Chin J Traumatol. 2004;7: $175-178$.
12. Ucar T, Akyuz M, Kazan S, Tuncer R. Role of decompressive surgery in the management of severe head injuries: prognostic factors and patient selection. J Neurotrauma. 2005;22:1311-1318.

13. Kofke WA, Stiefel M. Monitoring and intraoperative management of elevated intracranial pressure and decompressive craniectomy. Anesthesiol Clin. 2007;25:579-603, x.

14. Qiu W, Zhang Y, Sheng H, et al. Effects of therapeutic mild hypothermia on patients with severe traumatic brain injury after craniotomy. J Crit Care. 2007;22:229-235.

15. Teasdale GM, Pettigrew LE, Wilson JT, Murray G, Jennett B. Analyzing outcome of treatment of severe head injury: a review and update on advancing the use of the Glasgow Outcome Scale. J Neurotrauma. 1998; 15:587-597.

16. Pettigrew LE, Wilson JT, Teasdale GM. Assessing disability after head injury: improved use of the Glasgow Outcome Scale. J Neurosurg. 1998;89:939-943.

17. Pettigrew LE, Wilson JT, Teasdale GM. Reliability of ratings on the Glasgow Outcome Scales from in-person and telephone structured interviews. J Head Trauma Rehabil. 2003;18:252-258.

18. Wilson JT, Pettigrew LE, Teasdale GM. Structured interviews for the Glasgow Outcome Scale and the extended Glasgow Outcome Scale: guidelines for their use. J Neurotrauma. 1998;15:573-585.

19. Signorini DF, Andrews PJ, Jones PA, Wardlaw JM, Miller JD. Predicting survival using simple clinical variables: a case study in traumatic brain injury. J Neurol Neurosurg Psychiatr. 1999;66:20-25.

20. Lobato RD, Rivas JJ, Cordobes F, et al. Acute epidural hematoma: an analysis of factors influencing the outcome of patients undergoing surgery in coma. $J$ Neurosurg. 1988;68:48-57.

21. Wilberger JE Jr, Harris M, Diamond DL. Acute subdural hematoma: morbidity, mortality, and operative timing. J Neurosurg. 1991;74: 212-218.

22. Sakas DE, Bullock MR, Teasdale GM. One-year outcome following craniotomy for traumatic hematoma in patients with fixed dilated pupils. J Neurosurg. 1995;82:961-965.

23. Clusmann H, Schaller C, Schramm J. Fixed and dilated pupils after trauma, stroke, and previous intracranial surgery: management and outcome. J Neurol Neurosurg Psychiatr. 2001;71:175-181.

24. Leitgeb J, Mauritz W, Brazinova A, et al. Glasgow Coma Scale score at intensive care unit discharge predicts the 1-year outcome of patients with severe traumatic brain injury. Eur J Trauma Emerg Surg. 2013;39: 285-292.

25. Krieger D, Adams HP, Schwarz S, Rieke K, Aschoff A, Hacke W. Prognostic and clinical relevance of pupillary responses, intracranial pressure monitoring, and brainstem auditory evoked potentials in comatose patients with acute supratentorial mass lesions. Crit Care Med. 1993;21:1944-1950.

26. Ropper AH. The opposite pupil in herniation. Neurology. 1990;40: 1707-1709.

27. Ritter AM, Muizelaar JP, Barnes T, et al. Brain stem blood flow, pupillary response, and outcome in patients with severe head injuries. Neurosurgery. 1999;44:941-948.

28. Coplin WM, Cullen NK, Policherla PN, et al. Safety and feasibility of craniectomy with duraplasty as the initial surgical intervention for severe traumatic brain injury. J Trauma. 2001;50:1050-1059.

29. Munch E, Horn P, Schurer L, Piepgras A, Paul T, Schmiedek P. Management of severe traumatic brain injury by decompressive craniectomy. Neurosurgery. 2000;47:315-322; discussion 322-313.

30. Yoo DS, Kim DS, Cho KS, Huh PW, Park CK, Kang JK. Ventricular pressure monitoring during bilateral decompression with dural expansion. J Neurosurg. 1999;91:953-959.

31. Grady MS. Decompressive craniectomy. J Neurosurg. 2006;104: 467-468; discussion 468.

32. Honeybul S, Ho KM. Long-term complications of decompressive craniectomy for head injury. J Neurotrauma. 2011;28:929-935.

33. Olivecrona M, Rodling-Wahlstrom M, Naredi S, Koskinen LO. Effective ICP reduction by decompressive craniectomy in patients with severe traumatic brain injury treated by an ICP-targeted therapy. J Neurotrauma. 2007;24:927-935. 
Therapeutics and Clinical Risk Management

Dovepress

\section{Publish your work in this journal}

Therapeutics and Clinical Risk Management is an international, peerreviewed journal of clinical therapeutics and risk management, focusing on concise rapid reporting of clinical studies in all therapeutic areas, outcomes, safety, and programs for the effective, safe, and sustained use of medicines. This journal is indexed on PubMed Central, CAS,

EMBase, Scopus and the Elsevier Bibliographic databases. The manuscript management system is completely online and includes a very quick and fair peer-review system, which is all easy to use. Visit http://www.dovepress.com/testimonials.php to read real quotes from published authors.

Submit your manuscript here: http://www.dovepress.com/therapeutics-and-clinical-risk-management-journal 